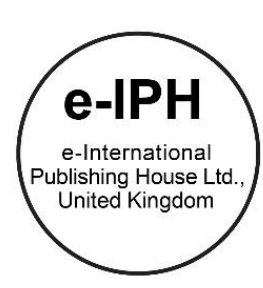

\title{
The Association of Awareness and Knowledge of Diabetic Retinopathy with Age and Residential Area In Selangor
}

\author{
Noor Halilah Buari 1,2, Nur Izzaty Dian ${ }^{1}$ \\ 1 Optometry, Faculty of Health Sciences, Universiti Teknologi MARA, 42300 Bandar Puncak Alam, Selangor, Malaysia \\ 2 Optometry and Visual Sciences Research Center (iROViS), Health and Wellbeing Community of Research, Universiti Teknologi MARA (UiTM), Shah Alam 40450 \\ Selangor, Malaysia \\ noorhalilah.buari@gmail.com \\ Tel:+60126121582
}

\begin{abstract}
The association of the awareness and knowledge of diabetic retinopathy with the age and residential area were investigated among selected Selangor populations. A cross sectional study was conducted using open-ended questions. Only half of the selected population was aware and had knowledge of diabetic retinopathy. The awareness was significantly associated with the age among urban and rural residential population but not with residential area. Health education programs could be suggested to increase the awareness of diabetic retinopathy among the population. By having awareness and knowledge, early complications of the diabetic can be detected and prevention can be secured, thus, improved one's quality of life.
\end{abstract}

Keywords: awareness; knowledge; diabetic retinopathy; diabetes

eISSN: 2398-4287@ 2017. The Authors. Published for AMER ABRA by e-International Publishing House, Ltd., UK. This is an open access article under the CC BYNCND license (http://creativecommons.org/licenses/by-nc-nd/4.0/). Peer-review under responsibility of AMER (Association of Malaysian Environment-Behaviour Researchers), ABRA (Association of Behavioural Researchers on Asians) and cE-Bs (Centre for Environment-Behaviour Studies), Faculty of Architecture, Planning \& Surveying, Universiti Teknologi MARA, Malaysia.

https://doi.org/10.21834/e-bpj.v2i6.942

\subsection{Introduction}

Diabetes mellitus is a chronic systemic disease that could lead to various ocular complications. The diabetes progression among Malaysian population was quite alarming. The prevalence has increased tremendously from $14.9 \%$ to $80 \%$ within 10 years especially among young adults aged 30 years and above $(\mathrm{MOH}, 2008)$. Diabetic retinopathy (DR) is an ocular complication of diabetes which represented as a progressive disease of retinal microvasculature that associated with prolonged hyperglycaemia and other conditions that linked to the diabetes mellitus (Negi \& Vernon, 2003). The prevalence of diabetic retinopathy ranged between $1.9 \%$ to $6.8 \%$ in developed countries (Bek et al., 2009; Looker et al., 2012; McKay et al., 2000), while in developing countries, the prevalence ranged from 14.9\% to 32.5\% (Glover et al., 2012; Goh et al., 2010; Kim et al., 2011).

In Malaysia approximately $58 \%$ of the diabetic patients showed characteristics and signs of diabetic retinopathy. From those who presented with retinopathies, $21 \%$ aged of 40 years and above (Naveen et al., 2014). Data from diabetic eye registry in Malaysia showed that the prevalence of diabetic retinopathy was $36.8 \%$ and $14.7 \%$ of the patients had sight-threatening diabetic retinopathy (Goh et al., 2010; Squirrell \& Talbot, 2003). A study on one hundred and thirty-seven diabetic patients attended eye clinic in University Malaya showed that diabetic retinopathy was detected in 40 diabetes patients which contributed about 29\% (Tajunisah et al., 2006). Majority of the patients who had retinopathies was those at the age of 61 to 70 years (Tajunisah et al., 2006). The associated factors of diabetic retinopathy were longer duration of diabetes (Kim et al., 2011; McKay et al., 2000), higher blood pressure (Bek et al., 2009; Looker et al., 2012) and high level of blood glucose (Bek et al., 2009; Kim et al., 2011; Looker et al., 2012).

eISSN: 2398-4287C 2017. The Authors. Published for AMER ABRA by e-International Publishing House, Ltd., UK. This is an open access article under the CC BYNCND license (http://creativecommons.org/licenses/by-nc-nd/4.0/). Peer-review under responsibility of AMER (Association of Malaysian Environment-Behaviour Researchers), ABRA (Association of Behavioural Researchers on Asians) and cE-Bs (Centre for Environment-Behaviour Studies), Faculty of Architecture, Planning \& Surveying, Universiti Teknologi MARA, Malaysia.

https://doi.org/10.21834/e-bpj.v2i6.942 
The awareness of the disease is defined as the state of being aware about selected disease by heard some of the information or being conscious of that disease (Zhang et al., 2016) either with or without knowledge about that particular disease. The knowledge is the understanding, attitude to patient's perception, any preconceived ideas they may have and practice in which patients demonstrate towards eye disease and services regarding eye care (Al Zarea, 2016). Previous study on diabetic type 2 who attended the eye clinic for the first time was found had higher awareness (86\%) of diabetic ocular complication (Tajunisah et al., 2011). Higher awareness was also found among those with tertiary education. However, lack of understanding of diabetic retinopathy with regards to never went for an ocular examination and also frequencies of follow up was found among those who had awareness. This was supported that among $50 \%$ to $55 \%$ who knew about diabetes mellitus they never went for an eye check up (Addoor, 2011; Goh et al., 2010). Another study also showed high awareness (87.2\%) of diabetes could affect the eye (Addoor, 2011). The awareness of diabetic retinopathy was also revealed high among Turkish diabetic patient which approximately $88 \%$. The diabetes patients also aware that early diagnosis was possible for diabetic retinopathy and could prevent severe complications (Çetin et al., 2013). Similarly in Saudi Arabia, high awareness (76\%) was shown among diabetes who knew that diabetes could cause eye disorders and the patients should go for a regular eye examination (Al Zarea, 2016).

The awareness of ocular manifestation of diabetes in several rural area were 37.1\% (rural India), 45.7\% (Bagalkot), 49\% (Ghana), and 63.3\% (Nepal) (Ovenseri-Ogbomo et al., 2013; Rani et al., 2008; Shetgar et al., 2015; Thapa et al., 2012). Majority of the studies was done among diabetes mellitus patients in hospital except for study in rural India which was conducted among public population (Rani et al., 2008). In Nepal, during the awareness investigation among diabetes patients, it was found that $78 \%$ had retinopathies, $16.7 \%$ had proliferative stage and $40 \%$ had significant diabetic macula edema (Thapa et al., 2012). This showed that lack of awareness of diabetic retinopathy; the patients could have low knowledge of the disease and missed the symptoms or signs that occurred due to ocular complications. Lower knowledge of DR also lead to reduced the right attitude towards practice and service of the eye care. Despite higher awareness of diabetic retinopathy that could lead to blindness among diabetic patients in Kano Nigeria, only $15.7 \%$ of then ever had an eye check up (Mohammed \& Waziri, 2009). It was also demonstrated that some of the diabetes patients had no or lower knowledge with regards to regular eye check up and the frequencies of follow up (Ovenseri-Ogbomo et al., 2013; Shetgar et al., 2015; Thapa et al., 2012). They did not know that eye examination is essential to those who own diabetic. The knowledge of DR was found low which $59 \%$ did not know which part of the eye could be affected due to diabetes (Bodunde et al., 2014). Only 14\% could report the involvement of retina as ocular complications of diabetes. Majority who had knowledge of ocular manifestation was those who had longer duration of diabetes (more than 10 years) (Ovenseri-Ogbomo et al., 2013). Good diabetic control was reported could prevent the retinopathies (Mohammed \& Waziri, 2009; Shetgar et al., 2015). The respondents informed that they retrieved knowledge of DR mostly from medical personnel such as doctors, physicians, hospital staff, nurses, general practitioners or optometrist (Mohammed \& Waziri, 2009; Ovenseri-Ogbomo et al., 2013; Shetgar et al., 2015; Thapa et al., 2015). This was followed by own having DR, family history and the mass media such as television, radio, newspaper or magazine (Shetgar et al., 2015).

The associated factors of diabetic retinopathy was found to be higher educational level, longer duration of diabetes mellitus and also previous education of diabetes (Addoor, 2011; Bodunde et al., 2014; Çetin et al., 2013; Katibeh et al., 2017). The knowledge of diabetic retinopathy was also related with the attitude to seek for an eye check up (Ovenseri-Ogbomo et al., 2013). The age of the patients especially those among 35 to 50 years were associated with the awareness of diabetic retinopathy (Addoor, 2011). In rural India, the knowledge of diabetic retinopathy was significantly higher among women and those who belong to upper socioeconomic strata and spoke Malayalam language (Rani et al., 2008). Among those who aware of diabetic retinopathy, little that knew the part of the eye that could be affected due to diabetic (Bodunde et al., 2014). The urban dwellers that had higher education level showed more awareness of DR than those from rural area (Katibeh et al., 2017).

Prevalence of ocular complications due to diabetic was higher, however the some of the patients still had lack of knowledge and understanding about the diabetic retinopathy in term of the characteristics, signs, symptoms and the risk factors. Some of diabetic patients even though had awareness; the level of understanding is still low and ignores the needs of regular eye examination. By having knowledge and understanding, patients could self-detect the early signs of ocular complications that can lead to the vision impairment and blindness. Hence, this study was conducted to investigate the level of awareness and knowledge of diabetic retinopathy in selected urban and rural populations. The association of the level of awareness with the age and residential area was also determined.

\subsection{Materials and methods}

The study opted a cross-sectional study design in which intended to determine level of awareness and knowledge of diabetic retinopathy in selected rural and urban residential public populations. It was conducted in ljok, Selangor as the rural residential area and Shah Alam, Selangor that represented the urban residential area. Urban or rural residential area status was determined from the authorized local council of Shah Alam and Kuala Selangor, Selangor.

Open-ended question was used to interview respondents from each residential area through a convenience sampling technique. The sample size was calculated based on the knowledge and awareness of diseases in previous study. It was calculated using this formula: $n=Z^{2} p(1-p) / d^{2}$. The $Z$ was the critical value from a normal distribution to desired confidence level $(Z=1.96$ for $95 \% \mathrm{Cl}), p$ was from the expected true proportion of the knowledge and awareness of the disease, 11.62\% (Zhang et al., 2016) and $d$ was the desired precision (0.07). From the calculation, 81 samples were computed. After taking the addition of $5 \%$ drops out, the total number of 
sample size was 86 respondents. Therefore, the respondents were conveniently recruited from each rural and urban residential, which gave a total of 172 respondents. The respondents were group into 5, which those in 20's, 30's, 40's, 50's and 60's. It was equally divided into 5 age groups to investigate the association of age with the awareness of DR. The inclusion criterion was the respondents who were living in the selected rural and urban population for at least 6 months. Those who were directly involved in diagnosis, treatment and management of diabetic retinopathy for example ophthalmologists and optometrists were excluded from this study.

The questionnaire used in this study was adopted from previous study on the awareness and knowledge of a disease (Pfeiffer et al., 2002). This questionnaire was selected for this study because it was an open-ended interview and was used to determine the level of awareness and knowledge among general population as this study was intended. Several other studies used semi-structured questionnaire with some guided answers for the respondents to choose. Thus, we could extract the response from the respondents, which purely from the knowledge that they might have without giving any clues or hints or choices of answers.

The questionnaire consisted of 7 questions that divided into 3 sections. In the first section the respondents were asked to fill up their socio-demographic data such as gender, age, residential area, the level of education and occupation. In the second and third sections, the interviewer asked the questions which needs the respondents' answer concerning the awareness and knowledge about diabetic retinopathy. The respondents were encouraged to answer without providing any clues or hints. The question no. 1 in the second section was asked about general knowledge of eye disease that the respondents ever know. The question no. 2 was asked to determine the whether the respondents ever heard or know about diabetic retinopathy. If they answered as 'no', the respondents were indicated as did not have awareness of diabetic retinopathy and they were given the brochure containing basic information about diabetic retinopathy. If the respondents answered as 'yes' in question no. 2, the interviewer proceed to the question no. 3 until no. 7. The third section comprised of question no. 3 to no. 7. This section indicated the knowledge of diabetic retinopathy. The question no. 3 was asked about the signs and symptoms of diabetic retinopathy. The sources of diabetic retinopathy information retrieved for the knowledge of diabetic retinopathy was asked in question no. 4. As in question no. 5, the interviewer asked the possible consequences of diabetic retinopathy. Then question no. 6 questioned about how to avoid the damage of diabetic retinopathy and the last question covered who are at the higher risk of diabetic retinopathy. All questions were asked verbally and the responds were captured and recorded for post-analysis.

Statistical analysis was performed using SPSS version 21.0 (SPSS Inc. Chicago, IL, USA). The data were stratified with the age, sex, educational level, profession, residential area, income, and others. The level of awareness and knowledge in selected rural and urban population was determined in frequencies and percentage. In order to compare the association of awareness between the age and residential areas, the Chi-Square test were used to investigate the association of level of awareness with the residential area and age groups. Data entry and statistical analysis were carried out using Statistical Package for Social Sciences (SPSS) software Version 21.0. Statistical significant was set at $p<0.05$.

\subsection{Results}

A total of 172 respondents were interviewed and women (69.2\%) were higher than men (30.8\%). The respondents were equally divided between the urban and rural residential population. The age ranged was between 20 years old until up to 70 years old and equally distributed into 5 age groups which the 20's, 30's, 40's, 50's and above 60's. In term of educational level, majority of the respondents had a secondary school (55.2\%) educational level followed with diploma certification, degree certification. Those who had master or Ph.D. education level (4.1\%) were the least. The highest numbers of the respondents worked at private sectors, 63 (36.6\%). The frequencies and percentage of the socio-demographic characteristics of the respondents were shown in Table 1.

Table 1. Distribution of demographic characteristics of the respondents

\begin{tabular}{lcc}
\hline Characteristics & Frequency (n) & Percentage (\%) \\
\hline Gender & 119 & \\
Female & 53 & $69.2 \%$ \\
Male & & $30.8 \%$ \\
Residential Area & 86 & \\
$\quad$ Urban & 86 & $50 \%$ \\
$\quad$ Rural & & $50 \%$ \\
Educational Level & & \\
$\quad$ Primary School & 17 & \\
$\quad$ Secondary School & 95 & $9.9 \%$ \\
$\quad$ Diploma & 35 & $55.2 \%$ \\
$\quad$ Degree & 18 & $10.5 \%$ \\
$\quad$ Master/PhD & 7 & $4.1 \%$ \\
& & \\
Occupation & 12 & $6.9 \%$ \\
$\quad$ Government Sector & 63 & $36.6 \%$ \\
Private Sector & 26 & $15.1 \%$ \\
Business & 54 & $31.4 \%$ \\
Housewife/not working & 17 & $9.9 \%$ \\
Others & &
\end{tabular}




\subsection{The awareness and knowledge of diabetic retinopathy}

Question number 2 determined the level of awareness of diabetic retinopathy among the respondents. It was found there were approximately equal between those who aware $(49.4 \%)$ and not aware $(50.6 \%)$ of diabetic retinopathy. The difference of awareness was very narrow about $1.2 \%$ only and it was illustrated in Fig. 1. Awareness of the diabetic retinopathy was then analyzed between the 5 age groups among the respondents, which were among the 20's, 30's, 40's, 50's and 60's. The highest awareness of the diabetic retinopathy was among the age group of 50's (29.4\%) and the lowest awareness was in the age group of 20's (8.2\%). The age groups of 30's, 40's and 60's represent awareness of $21.1 \%, 22.3 \%$ and $18.8 \%$ respectively.

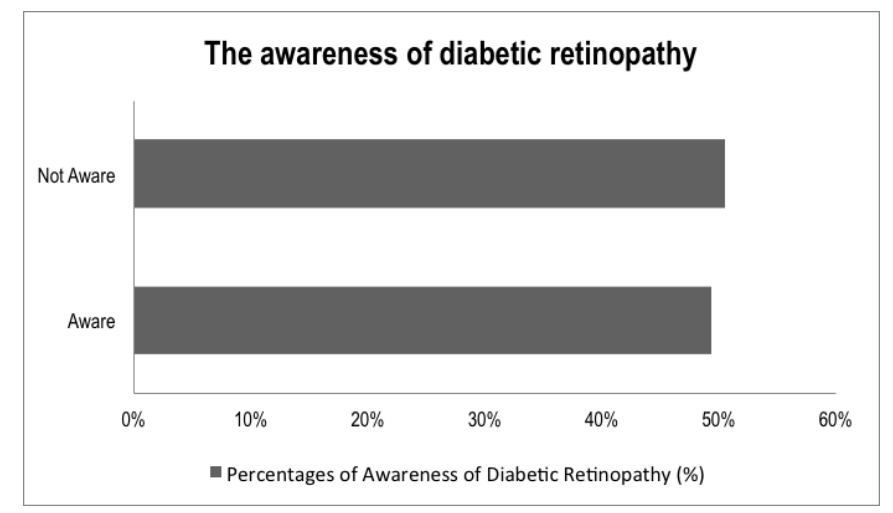

Fig. 1: The percentage of awareness of diabetic retinopathy among the respondents.

The knowledge for diabetic retinopathy among the respondents was tabulated in Table 2. From $49.4 \%$ respondents who were aware of diabetic retinopathy, they were then asked of any signs or symptoms of diabetic retinopathy they had known as in question 3 and the way they retrieved the information as in question 4 . The respondents who were aware mostly reported blurry of vision (67.1\%) followed by blindness (36.5\%) and sudden loss of vision (25.9\%). The least reported signs or symptoms of diabetic retinopathy were having difficulty in reading (3.5\%). However, there were several respondents (22.4\%) of those who aware were not sure about the signs and symptoms of diabetic retinopathy.

The source of information about diabetic retinopathy received by the respondents who were aware of diabetic retinopathy was asked. Majority of the respondents received information about diabetic retinopathy from their family members how had the disease, friends, vision or medical personnel, internet and from the newspaper. The least source of information retrieved was from the television.

Knowledge of diabetic retinopathy about possible consequences, prevention of diabetic retinopathy and risk of getting diabetic retinopathy was determined in questions number 5,6 and 7 . The percentages of this knowledge reported by the respondents were shown in Table 2. Sixty-two percent of respondents reported blurry of vision as possible consequences of diabetic retinopathy. The least reported by the respondents was a sudden loss of vision (3.5\%). Poor control of diabetes mellitus and longer duration of having diabetes mellitus was also reported as possible consequences. However, some of the respondents was not sure about it which $33 \%$ of the respondents from those who are aware.

The highest preventive measures thought by the respondents were to have a healthy lifestyle $(79.1 \%)$ followed by the control of diabetes (41.3\%) and seek for an early treatment (28.5\%). However, some of the respondents (8.1\%) were not sure about the answer. Despite some of them not sure about the answer, there was others answer given by the respondents, such as it cannot be treated (2.3\%).

Person or individual at the risk of getting diabetic retinopathy was also asked to the respondents as knowledge of diabetic retinopathy. The respondents stated that the diabetic patient was at higher risk of getting diabetic retinopathy. This was followed with geriatric people (55.8\%). Genetic factor also informed by the respondent to have higher chances in getting diabetic retinopathy (37.2\%). Some respondents assumed all people were equally at risk $(15.7 \%)$ to have diabetic retinopathy.

Table 2. Distribution pattern of knowledge of diabetic retinopathy

\begin{tabular}{ll}
\hline Knowledge characteristic & Frequency, $\mathbf{n}(\%)$ \\
\hline Signs and Symptoms $(\mathbf{n}=\mathbf{8 5})$ & \\
Blurry of Vision & $57(67.1 \%)$ \\
Blindness & $31(36.5 \%)$ \\
Sudden Loss of Vision & $22(25.9 \%)$ \\
Not Sure & $19(22.4 \%)$ \\
Retina Damage & $9(7.1 \%)$ \\
Difficulty Reading & $3(3.5 \%)$ \\
Source of information $(\mathbf{n}=85)$ & \\
Family History & $34(40 \%)$ \\
Friends & $23(27.1 \%)$ \\
\hline
\end{tabular}




\begin{tabular}{ll}
\hline Vision / medical personnel & $19(22.4 \%)$ \\
Internet & $13(11.8 \%)$ \\
Newspaper & $10(11.8 \%)$ \\
Others & $9(10.6 \%)$ \\
Television & $7(8.2 \%)$ \\
Possible Consequences ( $\mathbf{n}=172)$ & \\
Blurred Vision & $107(62.2 \%)$ \\
Poorly Controlled DM & $29(16.9 \%)$ \\
Long Term DM & $18(10,5 \%)$ \\
Sudden Loss Of Vision & $6(3.5 \%)$ \\
Not Sure & $57(33.1 \%)$ \\
Prevention of DR (n=172) & \\
Healthy Lifestyle & $136(79.1 \%)$ \\
Seek Early Treatment & $49(28.5 \%)$ \\
Control of Diabetes & $71(41.3 \%)$ \\
Others & $4(2.3 \%)$ \\
Not sure & $14(8.1 \%)$ \\
Risk of Getting DR (n=172) & \\
Diabetic Patient & $103(59.9 \%)$ \\
Geriatric & $96(55.8 \%)$ \\
Genetic & $64(37.2 \%)$ \\
All equal at risk & $27(15.7 \%)$ \\
Hypertension Patient & $4(2.3 \%)$ \\
Not sure & $2(1.2 \%)$ \\
\hline
\end{tabular}

\subsection{The association of diabetic retinopathy awareness with age and residential area}

The awareness of diabetic retinopathy was investigated if they had an association between the age and residential area. The age was grouped into 5 which the 20 's, 30's, 40's, 50's and 60's. The residential area was divided into two, those who were living in the urban residential area and rural residential area. A significant association was found in the level of awareness with the age group in selected urban and rural residential area as $X(4, N=172)=19.71, p=0.001$. Majority of the respondents from urban residential area with any age groups excluding those in 50's showed higher awareness than those from rural residential area. The age group of 30's which the middle age group showed the highest percentage of difference in awareness of diabetic retinopathy between urban and rural residential area by $4.7 \%$. This was followed among those who were in 40 's and 60 's. About $1.2 \%$ differences of awareness was found in age of 20 years and 50 years with the least difference in percentages of awareness of diabetic retinopathy

As for total respondents, it was found that the level of awareness of diabetic retinopathy for urban residential area population was $55.3 \%$ and rural residential area population was $44.7 \%$, respectively. The level of awareness was about $10.6 \%$ higher in urban residential area than the rural residential area population. The Chi-Square test was done to evaluate the association of the awareness between urban and rural residential area. However, no significant association was found between the awareness with selected urban and rural residential area population $[X(1, N=172)=1.884, p=0.170]$.

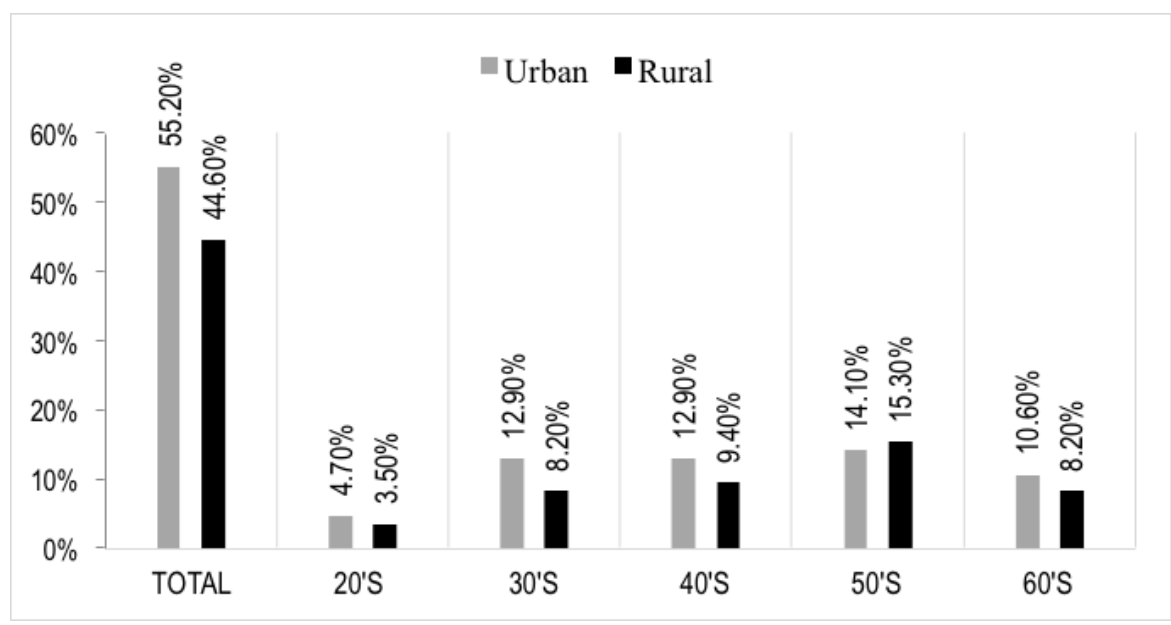

Fig. 2: Distribution of awareness for diabetic retinopathy based on age groups and residential area

\subsection{Discussion}

4.1 The awareness and knowledge of diabetic retinopathy 
The level of awareness among the respondents was about $49.4 \%$. It was indicated that only half of the total respondents aware of diabetic retinopathy. Those who were at 50's showed the highest awareness of diabetic retinopathy compared to the other age groups in 20's, 30's 40's and 60's. Lower awareness of diabetic retinopathy was also revealed in the study conducted in Ghana, Tamil Nadu India and Bagalkot which about 49\% (Ovenseri-Ogbomo et al., 2013), 37\% (Rani et al., 2008) and 45\% (Shetgar et al., 2015) respectively. The survey in rural Tamil Nadu Indian was conducted among the public Indian population during the diabetic retinopathy screening session (Rani et al., 2008). Similarly with our study, the interview was done among the public population but we did not examine the ocular health of the respondents. However, in Ghana and Bagalkot, it was conducted in the hospital based setting which the diabetic clinic among diabetes patients (Ovenseri-Ogbomo et al., 2013; Shetgar et al., 2015). Several other studies showed higher percentage of awareness for DR ranging from 76\% to 88\% (Al Zarea, 2016; Bodunde et al., 2014; Çetin et al., 2013; Mohammed \& Waziri, 2009). The awareness of diabetic retinopathy was also found to be higher in Malaysia which about $87 \%$ aware that diabetes could affect the eyes (Addoor, 2011; Tajunisah et al., 2006). This might be due to the selection of the respondents. Some studies conducted the survey of awareness among those who attended the hospital either at the endocrine clinic (Bodunde et al., 2014; Çetin et al., 2013), diabetic clinic (Addoor, 2011; Al Zarea, 2016) or eye clinic (Tajunisah et al., 2006). The selection of the respondents that among those who owned diabetes mellitus and came to the hospital for health examination could cause higher awareness that diabetes had ocular complications. Furthermore the studies opted semi-structured questionnaire that provided option of answers to be chosen from the lists. As compared to the current study, this survey of the awareness was conducted among the public population regardless they had diabetes mellitus or diabetic retinopathy, which we did, not asked. The open-ended questions were asked to the respondents without giving any clues or hints to gain pure response from the public weather the respondent have awareness and knowledge about diabetic retinopathy. This was design such a way to investigate of the actual awareness among the general population.

Blurry of vision was the common reported sign and symptom of diabetic retinopathy followed by the blindness. Blindness was have been aware that can caused due to diabetes mellitus (Addoor, 2011). In Turkish diabetes patients, higher awareness of diabetes complication that could effect the eyes (88\%) and vision (94\%) were reported (Çetin et al., 2013). The respondents were aware that diabetes was associated with blindness either it was a slow blindness or acute blindness. This was followed with intraocular hemorrhage and retinal detachment. A very extensive of diabetic retinopathy signs was reported by the respondents (Çetin et al., 2013). As compared in our study, the respondents stated blur vision, blindness, sudden vision loss and retinal damage for the signs of diabetic retinopathy complications. The responses reported by the respondents were quite similar with the previous study even though the method of survey was different. Our study interviewed the respondents while other study used self-administered questionnaire that given to the respondents with several options of answers (Çetin et al., 2013).

Majority of the respondents who was aware of diabetic retinopathy retrieved the information from the history of family members who had diabetic retinopathy or eye complications of diabetes mellitus. This was followed from history of their friends and from also from vision or medical personnel. It was agreed that communication with the health workers or medical personnel will increase the awareness and knowledge of diabetic retinopathy (Bodunde et al., 2014). Similarly, the leading source of information about ocular complication of diabetes was obtained form the hospital staff and the patients who owned diabetes (Mohammed \& Waziri, 2009; Shetgar et al., 2015; Tajunisah et al., 2006). The medical personnel such as ophthalmologist, optometrist and general practitioner were among healthcare professionals who have been chosen in the event of ocular problems due to diabetes (Al Zarea, 2016). Apart from it other sources of information was obtained from family or friends history, mass media such as television, internet, radio, newspaper, and also healthcare posters (Saleh et al., 2013; Shetgar et al., 2015).

Blurry of vision, poor control of diabetes mellitus and longer duration of diabetes mellitus were among possible consequences of diabetic retinopathy. The level of knowledge of diabetic retinopathy in this study was considered moderate which only half could reported the actual or correct information about diabetic retinopathy. Our study stated that opted a healthy life style and seeks for an early treatment could avoid the diabetic retinopathy. Healthy life style such as dietary modification and involvement in active life style could avoid the metabolic disorders and complications (Tudor \& Georgescu, 2013). Adopted active life style will keep a good physical and mental health in fast moving urban resident and showed could prevent from chronic diseases and improve one's quality of life (Mansor \& Harun, 2014). When the survey was conducted in public population, moderate (50\%) level of knowledge of diabetic retinopathy was also found among the respondents especially in the rural area (Rani et al., 2008). This showed that the public population still lack of knowledge and awareness of diabetic retinopathy. Some study showed that even though the respondents had higher awareness of diabetes mellitus could cause several ocular complications, a lot of them did not know that a regular eye examination was necessary to prevent the worse complications (Bodunde et al., 2014). Some of those who aware of diabetic retinopathy stated that there was no need of visit the ophthalmologist for an eye examination if the diabetes was under controlled (Al Zarea, 2016). However, poor control and longer duration of diabetes mellitus were also commonly reported among those with ocular consequences of diabetic retinopathy (Addoor, 2011; Bodunde et al., 2014; Mohammed \& Waziri, 2009). The duration of diabetes that more than 11 years had 3.7 times more likely to developed ocular complications of diabetes (Addoor, 2011).

\subsection{The association of diabetic retinopathy awareness with age and residential area}

The awareness of diabetic retinopathy was associated with the age but not with the residential area. However, those in urban residential area showed higher awareness of diabetic retinopathy than respondents in rural residential area. As in our study, the age was found to be associated with the knowledge of diabetic retinopathy (Addoor, 2011). The study divided the respondents' age into three groups i.e 35 - 50 years, 51-60 years and 61 - 86 years. A significant association was shown in those with age of $35-50$ years. 
That revealed the younger generation had more awareness the ocular consequences of diabetes. The similar pattern was revealed in our study which when the percentage of diabetic retinopathy in both urban and rural residential areas was combined and the age group was rearranged as in Addoor's study, those in $35-50$ years showed the highest awareness of diabetic retinopathy (43.4\%). However, the age selected of Addoor's study was imbalance across the groups and sample for each group was not equally distributed. Despite of younger age who shown higher awareness of diabetic retinopathy, the older age (more than 80 years) was also had higher knowledge of diabetic retinopathy (Ovenseri-Ogbomo et al., 2013).

Even though the association of awareness with the residential area was not significant, it displayed that awareness among urban residents was a bit higher than rural residents. Similarly pattern was also showed which rural population had lower awareness of DR than the urban population. The awareness of diabetic retinopathy was found to be lower in rural population of Tamil Nadu India (Rani et al., 2008), Bagalkot (Shetgar et al., 2015) and Ghana population (Ovenseri-Ogbomo et al., 2013). Those in rural residential area had studied among traders and farmers who had diabetes, but lack of knowledge that diabetes could affect the eyes (OvenseriOgbomo et al., 2013). However, higher awareness was revealed in several urban areas, which approximated $84 \%$ was aware of retinopathy as a complication of diabetes mellitus (Mohammed \& Waziri, 2009). Higher awareness that showed in urban residential area might be due to the study was done among diabetes patients who attended the diabetic clinic. As compared to this study, it was performed in the public not at the hospital setting. Urban dweller with higher education displayed more awareness of diabetic retinopathy than those from the rural area (Katibeh et al., 2017). Previous study showed no significant association of age with the knowledge of eye and vision involvement in diabetes but those with higher education and longer duration of diabetes were significantly associated with the knowledge (Çetin et al., 2013; Tajunisah et al., 2006).

\subsection{Conclusion}

In conclusion, only half of the respondents had awareness of diabetic retinopathy in selected urban and rural residential areas of Selangor. The level of awareness was equal in both urban and rural residents. Moderated level of knowledge has been shown among the population and it was associated with the age especially in young adults age group. This indicated that the education and awareness campaign should be increased to improve the level of knowledge and awareness of diabetic retinopathy among the population. By improving the awareness, any complications of diabetic retinopathy could be self-detected by the patient and severe damage of the complication can be avoided with an early treatment. Therefore, blindness caused by the ocular complication of diabetes can be prevented and improve the patients' quality of life.

\section{Acknowledgement}

The authors gratefully acknowledge the team members of this research project (Nurul Syazwani and Nasiha Shakina), which involved in several parts of the research area and also the respondents who made this paper possible. Thank you to the selected research site authorities that gave permission to us in conducting the study.

\subsection{References}

Addoor, K. R. (2011). Assessment of awareness of diabetic retinopathy among the diabetics attending the peripheral diabetic clinics in Melaka, Malaysia. Medical Journal of Malaysia, 66(1), 48-52.

Al Zarea, B. K. (2016). Knowledge, attitude and practice of diabetic retinopathy amongst the diabetic patients of of AlJouf and Hail Province of Saudi Arabia. Journal of Clinical and Diagnostic Research, 10(5), NC05-NC08. http://doi.org/10.7860/JCDR/2016/19568.7862

Bek, T., Lund-Andersen, H., Hansen, A. B., Johnsen, K. B., Sandbæk, A., \& Lauritzen, T. (2009). The Prevalence of Diabetic Retinopathy in Patients with ScreenDetected Type 2 Diabetes in Denmark: The ADDITION Study. Acta Ophthalmologica, 87, 270-274.

Bodunde, O., Odusan, O., Ogunsemi, O., Ajibode, H., \& Raimi, T. (2014). Awareness of Ocular Complications of Diabetes Among Diabetic Patients In A Tertiary Hospital In Western, Nigeria. IOSR Journal of Dental and Medical Sciences, 13(6), 2279-861. Retrieved from www.iosrjournals.org

Çetin, E. N., Zencir, M., Fenkçi, S., Akin, F., \& Yildirim, C. (2013). Assessment of awareness of diabetic retinopathy and utilization of eye care services among Turkish diabetic patients. Primary Care Diabetes, 7(4), 297-302. http://doi.org/10.1016/j.pcd.2013.04.002

Glover, S. J., Burgess, P. I., Cohen, D. B., Harding, S. P., Hofland, H. W. C., Zijlstra, E. E., \& Allain, T. J. (2012). Prevalence of Diabetic Retinopathy, Cataract and Visual Impairment in Patients With Diabetes in Sub-Saharan Africa. British Journal of Ophthalmology, 96, 156-161.

Goh, P. P., Omar, M. A., \& Yusoff, A. F. (2010). Diabetic Eye Screening in Malaysia: Findings From the National Health and Morbidity Survey 2006. Singapore Medical Journal, 51(8), 631-634.

Katibeh, M., Ahmadieh, H., Soleimanizad, R., \& Javadi, M. A. (2017). Awareness of the Necessity of Regular Eye Examinations among Diabetics: The Yazd Eye Study. International Journal of Preventive Medicine, 8(49), 1-7. http://doi.org/10.4103/ijpvm.IJPVM

Kim, J.-H., Kwon, H.-S., Park, Y.-M., Lee, J.-H., Kim, M.-S., Yoon, K.-H., ... Son, H.-Y. (2011). Prevalence and Associated Factors of Diabetic Retinopathy in Rural Korea: The Chungju Metabolic Disease Cohort Study. J Korean Med Sci, 26, 1068-1073. 
Looker, H., Nyangoma, S., Cromie, D., Olson, J., Leese, G., Black, M., ... Colhoun, H. (2012). Diabetic Retinopathy at Diagnosis of Type 2 Diabetes in Scotland. Diabetologia, 55, 2335-2342.

Mansor, M., \& Harun, N. Z. (2014). Health Issues and Awareness, and the Significant of Green Space for Health Promotion in Malaysia. Procedia - Social and Behavioral Sciences, 153, 209-220. http://doi.org/10.1016/j.sbspro.2014.10.055

McKay, R., McCarty, C. a, \& Taylor, H. R. (2000). Diabetic Retinopathy in Victoria, Australia: The Visual Impairment Project. The British Journal of Ophthalmology, 84, 865-870.

MOH, M. M. of H. (2008). The Second National Health and Morbidity Survey 2007. Diabetes mellitus among adults aged 30 years and above.

Mohammed, I., \& Waziri, A. (2009). Awareness of diabetic retinopathy amongst diabetic patients at the murtala mohammed hospital, Kano, Nigeria. Nigerian Medical Journal, 50(2), 38. http://doi.org/10.4314/nmj.v50i2.53541

Naveen-Kumar, T., Nagi-Reddy, T., \& Radha-Kishan, N. (2014). Diabetic eye screening in multi ethnic population of Malaysia: epidemiological risk factors for development of diabetic retinopathy. International Journal of Research in Medical Sciences, 2(3), 1045. http://doi.org/10.5455/2320-6012.jirms201408069

Negi, A., \& Vernon, S. a. (2003). An overview of the eye in diabetes. Journal of the Royal Society of Medicine, 96(6), 266-72. Retrieved from http://www.pubmedcentral.nih.gov/articlerender.fcgi?artid=539505\&tool=pmcentrez\&rendertype=abstract

Ovenseri-Ogbomo, G. O., Abokyi, S., Koffuor, G. a, \& Abokyi, E. (2013). Knowledge of diabetes and its associated ocular manifestations by diabetic patients: A study at Korle-Bu Teaching Hospital, Ghana. Nigerian Medical Journal : Journal of the Nigeria Medical Association, 54(4), 217-23. http://doi.org/10.4103/0300-1652.119602

Pfeiffer, N., Krieglstein, G. K., \& Wellek, S. (2002). Glaucoma Care Updates Knowledge about Glaucoma in the Unselected Population : A German Survey, 30432, 458463. http://doi.org/10.1097/01.IJG.0000030432.23569.7A

Rani, P. K., Raman, R., Subramani, S., Perumal, G., Kumaramanickavel, G., \& Sharma, T. (2008). Knowledge of diabetes and diabetic retinopathy among rural populations in India, and the influence of knowledge of diabetic retinopathy on attitude and practice. Rural and Remote Health, 8(3), 838. http://doi.org/838 [pii

Saleh, S. M., Azahari, M. H. H., \& Ismail, A. I. (2013). Diabetic Healthcare Awareness in Malaysia: The Role of Poster as a Communication Medium. Procedia - Social and Behavioral Sciences, 91, 539-544. http://doi.org/10.1016/j.sbspro.2013.08.452

Shetgar, A. C., Patil, B., Salagar, M. C., \& Nanditha, A. (2015). Assessment of awareness of diabetic retinopathy among diabetics: A Clinical Survey. Indian Journal of Clinical and Experimental Ophthalmology, 1(4), 260-263. http://doi.org/10.5958/2395-1451.2015.00024.4

Squirrell, D. M., \& Talbot, J. F. (2003). Clinical Practice Guidelines. Journal of the Royal Society of Medicine, 96(6), 273-276. http://doi.org/10.1002/pdi.299

Tajunisah, I., Nabilah, H., \& Reddy, S. C. (2006). Prevalence and risk factors for diabetic retinopathy--a study of 217 patients from University of Malaya Medical Centre. The Medical journal of Malaysia, 61(4), 451. The Medical Journal of Malaysia, 61(4), 451. Retrieved from http://www.ncbi.nlm.nih.gov/pubmed/17243523

Tajunisah, I., Wong, P., Tan, L., Rokiah, P., \& Reddy, S. (2011). Awareness of Eye Complications and Prevalence of Retinopathy in The First Visit to Eye Clinic Among Type 2 Diabetic Patients. International Journal of Ophthalmology, 4(5), 519-524.

Thapa, R., Bajimaya, S., Paudyal, G., Khanal, S., Tan, S., Thapa, S. S., \& van Rens, G. (2015). Population awareness of diabetic eye disease and age related macular degeneration in Nepal: the Bhaktapur Retina Study. BMC Ophthalmology, 15(1), 188. http://doi.org/10.1186/s12886-015-0175-z

Thapa, R., Paudyal, G., Maharjan, N., \& Bernstein, P. (2012). Demographics and awareness of diabetic retinopathy among diabetic patients attending the vitreo-retinal service at a tertiary eye care center in Nepal. Nepalese Journal of Ophthalmology, 4(1), 10-16. http://doi.org/10.3126/nepjoph.v4i1.5844

Tudor, M. I., \& Georgescu, L. (2013). A Correlational Study of the Relationship between Lifestyle Knowledge and Metabolic Disorders. Procedia - Social and Behavioral Sciences, 76(LC), 842-847. http://doi.org/10.1016/j.sbspro.2013.04.217

Zhang, B., Gao, J.-G., Pan, C., Luan, M., \& Chen, X.-M. (2016). Awareness and knowledge about cataract, glaucoma, and age-related macular degeneration in Chengdu, China. International Eye Science, 16(3), 397-402. http://doi.org/10.3980/j.issn.1672-5123.2016.3.01 